\title{
DUALITY IN NONLINEAR COMPLEMENTARITY THEORY BY USING INVERSIONS AND SCALAR DERIVATIVES
}

\author{
G. ISAC AND S. Z. NÉMETH
}

Abstract. The notion of infinitesimal exceptional family of elements will be introduced. By using a special inversion mapping a duality between the exceptional family of elements and the infinitesimal exceptional family of elements will be presented. By using this duality and the notion of scalar derivatives existence theorems for complementarity problems in Hilbert spaces will be presented. Remark (important!): The notion of duality will be introduced not for the sake of "playing" with a new notion, but in order to prove Theorem 8.8, which provides a powerful tool for solving complementarity problems.

Mathematics subject classification (2000): 90C33, 46T20, 46T20.

Key words and phrases: nonlinear complementarity problems, exceptional family of elements, infinitesimal exceptional family of elements, inversions, scalar derivatives.

\section{REFERENCES}

[1] V. A. BULAVSKI, G. ISAC AND V. V. KALASHNIKOV, Application of topological degree to complementarity problems, In: Multilevel Optimization: Algorithms and Applications (Eds. A. Migdalas, P. M. Pardalos and P. Warbrant) Kluwer Academic Publishers, pp. 333-358, 1998.

[2] V. A. Bulavski, G. Isac And V. V. Kalashnikov, Application of topological degree theory to semi-definite complementarity problem, Optimization, 49, (5-6), (2001), 405-423.

[3] A. CARbone, P. P. Zabreiko, Some remarks on complementarity problems in a Hilbert space, Anal. Anw., 21, (2002), 1005-1014.

[4] M. P. DO CARMO, Riemannian Geometry, Birkhäuser, Boston, 1992.

[5] G. Choquet, Outiles Topolologiques et Metriques de l'Analyse Mathematiques (Cours Redige par Claude Mayer) Centre de Documentation Universitaire et S.E.D.E.S., Paris - V, 1969.

[6] D. H. Hyers, G. ISAC AND TH. M. Rassias, Topics in Nonlinear Analysis and Applications, World Scientific, Singapore, New Jersey, London, Hong Kong, 1997.

[7] G. IsAC, Complementarity Problems, Lecture Notes in Mathematics, Springer-Verlag, No. 1528, 1992.

[8] G. IsAC, Topological Methods in Complementarity Theory, Kluwer Academic Publishers, 2000.

[9] G. ISAC, A generalization of Karamardian's condition in complementarity theory, Nonlinear Analysis Forum, 4, (1999), 49-63.

[10] G. IsAC, Exceptional family of elements, feasibility, solvability and continuous path of $\varepsilon$-solutions for nonlinear complementarity problems, In: Approximation and Complexity in Numerical Optimization: Continuous and Discrete Problems, (Ed, Panos M. Pardalos), Kluwer Academic Publishers, pp. 323-337, 2000.

[11] G. IsAC, On the solvability of multivalued complementarity problem: A Topological method, Fourth European Workshop on Fuzzy Decision Analysis and Recognition Technology, EFDAN"99, Dorthmund, Germany, June 14-15, (Ed. R. Felix), 51-66.

[12] G. ISAC, Leray-Schauder type alternatives and the solvability of complementarity problems, Topological Methods in Nonlinear Analysis, 18, (2001), 191-204.

[13] G. IsAC, On the solvability of complementarity problems by Leray-Schauder type alternatives, Libertas Mathematica, 20, (2000), 15-22.

[14] G. Isac, V. A. BulaVsKi AND V. V. Kalashnikov, Exceptional families, topological degree and complementarity problems, Journal of Global Optimization, 10, (2) (1997), 207-225. 
[15] G. IsaC, V. A. BUlavski AND V. V. Kalashnikov, Complementarity, Equilibrium, Efficiency and Economics, Kluwer Academic Publishers, 2002.

[16] G. ISAC, A. CARBONE, Exceptional families of elements for continuous functions: Some applications to complementarity theory, Journal of Global Optimization, 15, (2) (1999), 181-196.

[17] G. IsAC, M. G. COJOCARU, Functions without exceptional family of elements and the solvability of variational inequalities on unbounded sets, Topological Methods in Nonlinear Analysis, 20, (2002), 375-391.

[18] G. IsaC, V. V. KaLASHNIKov, Exceptional families of elements, Leray-Schauder alternative, pseudomonotone operators and complementarity, Journal of Optimization Theory and Application, 109, (1) (2001), 69-83.

[19] G. IsaC, M. M. KostreVa AND M. PolyashuK, Relational complementarity problem, From local to Global Optimization, A. Migdalas et al (eds.), Kluwer Academic Publishers, 327-339, 2001.

[20] G. IsAC, S. Z. NÉMETH, Scalar derivatives and scalar asymptotic derivatives. Properties and some applications, Journal of Mathematical Analysis and Applications, 278, (1) (2003), 149-170.

[21] G. IsAC, S. Z. NÉMETH, Scalar derivatives and scalar asymptotic derivatives. An Altman type fixed point theorem on convex cones and some applications, Journal of Mathematical Analysis and Applications, 290, (2) (2004), 452-468.

[22] G. IsAC, W. T. OBUCHOWSKA, Functions without exceptional families of elements and complementarity problems, Journal of Optimization Theory and Applications, 99, (1) (1998), 147-163.

[23] G. IsAC, Y. B. ZHAO, Exceptional families of elements and the solvability of variational inequalities for unbounded sets in infinite dimensional Hilbert spaces, Journal of Mathematical Analysis and Applications, 246, (2) (2000), 544-556.

[24] V. V. Kalashnikov, Complementarity Problem and the Generalized Oligopoly Model, Habilitation Thesis, CEMI, Moscow, 1995.

[25] V. V. KALASHNIKOV, G. ISAC, Solvability of implicit complementarity problems, Annals of Operations Research, 116, (2002), 199-221.

[26] S. Z. NÉMETH, A scalar derivative for vector functions, Rivista di Matematica Pura ed Applicata, (10) (1992), 7-24.

[27] S. Z. NÉMETH, Scalar derivatives and spectral theory, Mathematica, Thome 35 (58), (1) (1993) 49-58.

[28] W. T. OBUCHOWSKA, Exceptional families and existence results for nonlinear complementarity problem, Journal of Global Optimization, 19, (2) (2001) 183-198.

[29] Y. B. ZHAO, Existence Theory and Algorithms for Finite-Dimensional Variational Inequality and Complementarity Problems, Ph.D. Dissertation Institute of Applied Mathematics, Academia SINICA, Beijing, (China), 1998.

[30] Y. B. ZHAO, $d$-orientation sequences for continuous and nonlinear complementarity problems, Applied Mathematics and Computation, 106, (2-3) (1999), 221-235.

[31] Y. B. ZHAO, J. Y. HAN, Exceptional family of elements for variational inequality problem and its applications, Journal of Global Optimization, 14, (3) (1999), 313-330.

[32] Y. B. ZHAO, J. Y. HAN AND H. D. QI Exceptional families and existence theorems for variational inequality problems, Journal of Optimization Theory and Applications, 101, (2) (1999), 475-495.

[33] Y. B. ZHAO, G. ISAC, Quasi-P *-maps and $P(\tau, \alpha, \beta)$-maps, exceptional family of elements and complementarity problems, Journal of Optimization Theory and Applications, 105, (1) (2000), 213 231.

[34] Y. B. ZHAO, G. ISAC, Properties of multivalued mapping associated with some nonmonotone complementarity problems, SIAM Journal of Control and Optimization, 39, (2) (2000), 571-593.

[35] Y. B. ZHAO, D. LI, Strict feasibility conditions in nonlinear complementarity problems, Journal of Optimization Theory and Applications, 107, (2) (2000), 641-664.

[36] Y. B. ZHAO, D. LI, Characterizations of a homotopy solution mapping for quasi-and semi-monotone complementarity problems, Preprint, Academia SINCA, Beijing, (China), 2001.

[37] Y. B. ZHAO, D. LI, On a new homotopy continuation trajectory for nonlinear complementarity problems, Mathematics of Operations Research, 26, (1) (2001), 119-146.

[38] Y. B. ZHAO, D. SUN, Alternative theorems for nonlinear projection equations and applications, Nonlinear Analysis, Theory Methods \& Applications, 46A, (6) (2001), 853-868.

[39] Y. B. ZHAO, J. Y. YUAN, An alternative theorem for generalized variational inequalities and solvability of non-linear quasi- $P_{*}^{M}$-complementarity problems, Applied Mathematics and Computation, 109, (2-3) (2000), 167-182. 